\title{
Intensive Care in India in 2018-2019: The Second Indian Intensive Care Case Mix and Practice Patterns Study
}

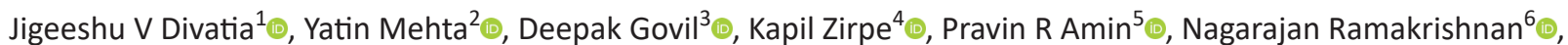
Farhad N Kapadia ${ }^{7}$, Mrinal Sircar ${ }^{8} \odot$, Samir Sahu ${ }^{\oplus}$, Pradip Kumar Bhattacharya ${ }^{10}{ }^{\circ}$, Sheila Nainan Myatra ${ }^{11}$, Srinivas

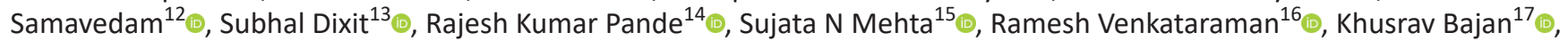

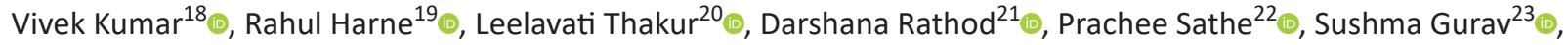
Carol D’Silva ${ }^{24}{ }^{\circ}$, Shaik Arif Pasha ${ }^{25}$, Subhash Kumar Todi $^{26}{ }_{\odot}$, the INDICAPS-II investigators

\begin{abstract}
Background: We aimed to study organizational aspects, case mix, and practices in Indian intensive care units (ICUs) from 2018 to 2019 , following the Indian Intensive Care Case Mix and Practice Patterns Study (INDICAPS) of 2010-2011.

Methods: An observational, 4-day point prevalence study was performed between 2018 and 2019. ICU, patient characteristics, and interventions were recorded for 24 hours, and ICU outcomes till 30 days after the study day. Adherence to selected compliance measures was determined. Data were analyzed for 4,669 adult patients from 132 ICUs.

Results: On the study day, mean age, acute physiology and chronic health evaluation (APACHE II), and sequential organ failure assessment (SOFA) scores were $56.9 \pm 17.41$ years, $16.7 \pm 9.8$, and $4.4 \pm 3.6$, respectively. Moreover, $24 \%$ and $22.2 \%$ of patients received mechanical ventilation (MV) and vasopressors or inotropes (VIs), respectively. On the study days, 1,195 patients (25.6\%) were infected and 1,368 patients (29.3\%) had sepsis during their ICU stay. ICU mortality was 1,092 out of 4,669 (23.4\%), including 737 deaths and 355 terminal discharges (TDs) from ICU. Compliance for process measures related to MV ranged between 62.7 and $85.3 \%, 11.2$ and $47.4 \%$ for monitoring delirium, sedation, and analgesia, and 7.7 and $25.3 \%$ for inappropriate transfusion of blood products. Only $34.8 \%$ of ICUs routinely used capnography. Large hospitals with $\geq 500$ beds, closed ICUs, the APACHE II and SOFA scores, medical admissions, the presence of cancer or cirrhosis of the liver, the presence of infection on the study day, and the need for MV or VIs were independent predictors of mortality.

Conclusions: Hospital size and closed ICUs are independently associated with worse outcomes. The proportion of TDs remains high. There is a scope for improvements in processes of care.

Registered at clinicaltrials.gov (NCT03631927).

Keywords: Adult, Health care, India, Intensive care units, Mortality, Patients, Process assessment.

Indian Journal of Critical Care Medicine (2021): 10.5005/jp-journals-10071-23965
\end{abstract}

\section{INTRODUCTION}

The Indian Intensive Care Case Mix and Practice Patterns Study (INDICAPS) was the first large-scale, multicenter survey that gathered information about intensive care units and practices in India. This multicenter study of 4,038 adult patients from 120 ICUs conducted between July 2010 and April 2011 provided a snapshot of intensive care in India. Highlights included a moderate severity of illness with relatively high mortality in patients with severe sepsis and septic shock, and those receiving vasopressors or inotropes (VIs) or mechanical ventilation (MV). Self-paying patients, public hospital ICUs, and inadequately equipped ICUs were independently associated with ICU mortality, and terminal discharge (TD) from the ICU was widely practiced. Over the next several years, there has been a significant change in the delivery of intensive care services, critical care education, socioeconomic indicators, antibiotic use, resistance patterns, and other aspects of practices in Indian ICUs. Hence the second Indian Intensive Care Case Mix and Practice Patterns Study (INDICAPS-II) was performed to revisit and study the practice of intensive care in India in the years 2018 and 2019.

\section{Patients and Methods}

This was a multicenter, observational, staggered point prevalence study performed on four separate days: August 23, 2018; October 25,

\footnotetext{
${ }^{1}$ Department of Anaesthesiology, Critical Care and Pain, Tata Memorial Hospital, Homi Bhabha National Institute, Mumbai, Maharashtra, India 2,3,19 Medanta Institute of Critical Care and Anaesthesia, Medanta-The Medicity, Gurugram, Haryana, India

${ }^{4}$ Neurotrauma and Stroke Unit, Ruby Hall Clinic, Pune, Maharashtra, India

${ }^{5}$ Department of Critical Care Medicine, Bombay Hospital and Medical Research Centre, Mumbai, Maharashtra, India

${ }^{6}$ Critical Care Services, Apollo Hospitals, Chennai, Tamil Nadu, India

7,17 Department of Intensive Care Medicine, PD Hinduja Hospital and MRC, Mumbai, Maharashtra, India

${ }^{8}$ Department of Pulmonology and Critical Care, Fortis Hospital, Noida, Uttar Pradesh, India

${ }^{9}$ Department of Critical Care and Pulmonology, AMRI Hospitals, Bhubaneswar, Odisha, India

${ }^{10}$ Department of Critical Care Medicine, Rajendra Institute of Medical Sciences, Ranchi, Jharkhand, India

${ }^{11}$ Department of Anaesthesiology, Critical Care and Pain, Tata Memorial Hospital, Homi Bhabha National Institute, Mumbai, Maharashtra, India

${ }^{12}$ Department of Critical Care Medicine, Virinchi Hospital, Hyderabad, Telangana, India

${ }^{13}$ Department of Critical Care, Sanjeevan Hospital, Pune, Maharashtra, India
} 
2018; December 13, 2018; and April 11, 2019. All ICUs in India, including participants from INDICAPS, were invited to participate through announcements on social media, at conferences, and on the website of the Indian Society of Critical Care Medicine (ISCCM). All investigators obtained approval from their respective hospital ethics committees. The study is registered at clinicaltrials.gov (NCT03631927).

The study protocol, forms, and instructions were uploaded on the study website (http://indicaps.isccm.org). Individual sites could contribute on any or all days of the study. All patients present in the ICU on the study days were included in the study. Data were recorded for all patients present in the ICU during the 24 hours starting from 08.00 a.m. on the study day to 08.00 a.m. the next day. Neonatal and pediatric ICUs were not included. There were no other exclusion criteria. All data were anonymized and submitted online through a dedicated website.

The first time an ICU joined the study, demographic data about the ICU were recorded. A closed ICU was defined as one in which final orders for the patient were written only by the ICU team; all other ICUs, where orders could be written by either the ICU team or the primary team, were considered as open ICUs. A center was considered adequately equipped if all the following facilities were available: renal replacement therapy (RRT) and echocardiography available in the ICU, computed tomography scan, microbiology, biochemistry and hematology laboratories, blood bank, and cardiac catheterization laboratory available in the hospital.

Primary reasons for ICU admission, source of admission, demographics, patient characteristics, and comorbidities were recorded. Admission was defined as surgical if the patient was admitted to the ICU from the operation theater or recovery room. Elective surgery was defined as a surgical procedure that was planned more than 24 hours before ICU admission. Emergency surgery was defined as a surgical procedure before ICU admission that was planned $<24$ hours in advance. The primary reason for ICU admission was the single most applicable diagnostic category based on the acute physiology and chronic health evaluation (APACHE) III classification. ${ }^{2}$

Age, physiological parameters, and comorbidities were collected and used to calculate the APACHE II score ${ }^{3}$ and sequential organ failure assessment (SOFA) score. ${ }^{4}$ Physiological variables used for the calculation were the worst recorded values during the 24-hour study period. When data for any parameter required calculation of the APACHE II and SOFA score were missing, that parameter was assumed to be normal. A SOFA score of 3 or 4 for any individual organ was used to identify organ failure.

The presence of infection (suspected or proven infection at ICU admission or during the 24-hour study period) was recorded. Tropical infection (malaria, dengue, leptospirosis, or scrub typhus) was diagnosed based on a positive laboratory test. Sepsis was diagnosed if the investigators entered a diagnostic code for sepsis, or if the patient had a SOFA score $\geq 2$ and suspected or confirmed infection on the study day, ${ }^{5}$ or confirmed tropical infection. Septic shock was recorded if the investigator entered a diagnosis of septic shock or when vasopressors were used in patients with sepsis as defined above. ${ }^{5}$ Data on cultured microorganisms were also recorded.

ICU survival status was recorded up to 30 days from the day of the study. Patients discharged alive from ICU were followed till hospital discharge, or 30 days from the day of the study, whichever was earlier. For patients dying in the ICU, investigators were asked to record whether any form of limitation of treatment occurred.
${ }^{14}$ Department of Critical Care Medicine, BLK Super Speciality Hospital, Delhi, India

${ }^{15}$ Department of Medicine and Critical Care, Bombay Hospital and Medical Research Centre, Mumbai, Maharashtra, India

${ }^{16}$ Department of Critical Care Medicine, Apollo Hospitals, Chennai, Tamil Nadu, India

${ }^{18}$ Critical Care and Emergency Medical Services, Sir HN Reliance Foundation Hospital and Research Centre, Mumbai, Maharashtra, India ${ }^{20}$ Department of Critical Care, IQ City Medical College and Narayana Multispecialty Hospital, Durgapur, West Bengal, India

${ }^{21}$ Department of Critical Care, Sir HN Reliance Foundation Hospital, Mumbai, Maharashtra, India

${ }^{22}$ Department of Critical Care Medicine, Ruby Hall Clinic, Pune, Maharashtra, India

${ }^{23}$ Neurotrauma Unit, Ruby Hall Clinic, Pune, Maharashtra, India

${ }^{24}$ Department of Critical Care Medicine, St John's Medical College Hospital, Bengaluru, Karnataka, India

${ }^{25}$ Department of Critical Care Medicine, NRI Medical College, Guntur, Andhra Pradesh, India

${ }^{26}$ Department of Critical Care Medicine, AMRI Dhakuria Hospital, Kolkata, West Bengal, India

Corresponding Author: Jigeeshu V Divatia, Department of Anaesthesiology, Critical Care and Pain, Tata Memorial Hospital, Homi Bhabha National Institute, Mumbai, Maharashtra, India, Phone: +91 9869077435, e-mail: jdivatia@yahoo.com

How to cite this article: Divatia JV, Mehta Y, Govil D, Zirpe K, Amin PR, Ramakrishnan N, et al. Intensive Care in India in 2018-2019: The Second Indian Intensive Care Case Mix and Practice Patterns Study. Indian J Crit Care Med 2021;25(10):1093-1107.

Source of support: This study was funded by the Indian Society of Critical Care Medicine

Conflict of interest: None

TDs from ICU to a location outside the hospital, either on family or patient request, as well as those documented as left against medical advice, ${ }^{6}$ were recorded.

The primary outcome was ICU mortality, which included patients who died in the ICU, as well as TDs, up to 30 days from the day of the study. Secondary outcomes included hospital mortality (including patients who died in the hospital and TDs from the ICU within 30 days from the day of the study), and ICU and hospital lengths of stay, till 30 days from the study day.

The standardized mortality ratio (SMR) using the ratio of observed hospital mortality to the hospital-predicted mortality by APACHE II was calculated for those patients who were admitted to the ICU within 24 hours of the study day.

We also determined the adherence to selected process measures, including the presence of written protocols in the ICU, capnography to confirm tracheal intubation, use of subglottic suction and closed tracheal suction systems, administration of deep venous thrombosis (DVT) prophylaxis, and maintaining plateau pressure or peak airway pressure (during volume-controlled or pressure-controlled ventilation, respectively) $\leq 30 \mathrm{~cm} \mathrm{H} \mathrm{H}_{2} \mathrm{O}$ in patients receiving invasive $\mathrm{MV}$, and monitoring of sedation, analgesia, and delirium. ${ }^{7}$ We also determined the proportion of patients with inappropriate transfusion triggers of hemoglobin $(\mathrm{Hb})>9 \mathrm{~g} / \mathrm{dL}$ for packed red blood cell transfusion, international normalized ratio (INR) $\leq 1.5$ and activated partial thromboplastin time (APTT) $\leq 45$ for fresh frozen plasma (FFP), and platelet count $>50 \times 10^{3} / \mathrm{mm}^{3}$ for platelet transfusion. 
Prior training of investigators and verification of source data were not performed. However, an online investigator's discussion forum was formed to deal with queries and problems during the data entry. Investigators were contacted by E-mail to complete missing data.

\section{Analysis}

Analysis was performed for adult patients ( $\geq 16$ years of age), for whom ICU mortality was available. Continuous variables were compared with the use of the Student's $t$-test, analysis of variance, Mann-Whitney test, or the Kruskal-Wallis test. Categorical variables were compared using the chi-square test. A two-tailed $p<0.05$ was considered statistically significant. Multivariable binary logistic regression analysis (method Enter) was performed to determine the independent predictors of ICU mortality using ICU characteristics, patient factors, and interventions (RRT, MV, and VIs in the ICU) with a $p$-value of $\leq 0.1$ in the univariate analysis. All analyses were performed using $\mathrm{IBM}^{\oplus}$ SPSS $^{\circledast}$ Statistics version 20.0.0.

\section{Results}

A total of 5,222 patients from 141 ICUs were enrolled inclusive of all the four study days, of whom 5,094 were adults ( $\geq 16$ years of age). Data for the primary outcome were not available in 425 adults, resulting in the exclusion of these patients and nine ICUs. Data analysis was done for adult patients $(n=4,669)$ from 132 ICUs. Details of participation are provided in Supplementary Tables S1 to S4. Missing data for patient-related variables are summarized in Supplementary Table S5.

Table 1 summarizes the facilities available in the ICU or the hospital. In the study, the number per bed \{median [interquartile range, (IQR)]\} of invasive ventilators, noninvasive ventilators, and high-flow nasal oxygen (HFNO) were 0.51 (0.36-0.76), 0.14 (0.08-0.25), and $0(0-0.08)$, respectively. Sixty-two centers (47\%) were considered adequately equipped, whereas 70 (53\%) were categorized as "not adequately equipped."

Table 2 summarizes the characteristics of the 132 ICUs. The median (IQR) number of hospital beds, ICU beds, nurse: patient ratio, and full-time consultants per bed were 338(200-650),
20 (13.25-32.75), 0.55 (0.43-0.67), and 0.15(0.08-0.23), respectively. Most ICUs were in hospitals that were not accredited to the National Accreditation Board for Hospitals and Healthcare Providers (NABH) or the Joint Commission International (JCl). The vast majority of ICUs and patients were from private hospitals.

The primary APACHE III diagnostic categories are summarized in Table 3, and patient demographics, the severity of illness, and outcomes are detailed in Table 4. Overall, 737 out of 4,669 patients (15.8\%) died in the ICU, and an additional 355 patients were TDs from the ICU. Thus total ICU mortality including TDs was 1,092 out of 4,669 (23.4\%). The total hospital mortality was $25.3 \%$, which included 809 patients who died in the hospital and 355 TDs. The median (IQR) length of ICU stay was 6 (3-13) days, with significantly longer stays in nonsurvivors (Table 2). Figures $1 \mathrm{~A}$ and $1 \mathrm{~B}$ show the distribution of APACHE II scores and the number of organ failures with the associated ICU mortality. Almost $51 \%$ of patients did not have any organ failure on the study day; ICU mortality was $13.1 \%$ in these patients and $32 \%$ of patients did not have any comorbidities.

A subset of 1,854 patients was admitted within 24 hours of a study day, of which 1,819 had data for hospital outcomes. Of these, 398 patients were predicted to die in the hospital, whereas the observed hospital mortality was 368. The SMR was thus 0.92 . The APACHE II score generally predicted mortality well, except at scores $\geq 30$, when it overpredicted mortality, as seen in Figure 2.

Medical admissions accounted for $85.5 \%$ of admissions; they had a higher severity of illness than surgical admissions and significantly higher mortality. Mortality was significantly higher for admissions after emergency surgery than elective surgery (Table 4).

Sepsis with or without septic shock during the ICU stay was present in 1,368 patients (29.3\%), with ICU mortality of $36.9 \%$. During the 24-hour study period, 1,195 patients had a suspected or confirmed infection. A total of 4,609 microbiological cultures were obtained in 2,275 patients, and 1,304 organisms were identified in 902 patients. Gram-negative organisms accounted for $75.6 \%$, while gram-positive organisms, fungi, mycobacteria, and anaerobes accounted for $13.6,9.7$, and $0.46 \%$ of organisms identified, respectively. In addition, 87 patients (1.99\%) had a

Table 1: Facilities available in the ICU and in the hospital in 132 centers

\begin{tabular}{lccc}
\hline Facility & Available in ICU & Available in hospital & Not available \\
\hline Chest X-ray & $107(81.1)$ & $25(18.9)$ & $0(0.0)$ \\
Blood gas analysis & $96(72.7)$ & $35(26.5)$ & $1(0.8)$ \\
Ultrasonography (excluding echocardiography) & $104(78.8)$ & $26(19.7)$ & $2(1.5)$ \\
Echocardiography & $103(78.0)$ & $28(21.2)$ & $1(0.8)$ \\
Hemodialysis & $103(78.0)$ & $24(18.2)$ & $5(3.8)$ \\
Continuous renal replacement therapy & $61(46.2)$ & $19(14.4)$ & $52(39.4)$ \\
Fiber-optic bronchoscope & $76(57.6)$ & $50(37.9)$ & $6(4.5)$ \\
Blood bank & Not applicable & $109(82.6)$ & $23(17.4)$ \\
Platelet pheresis & Not applicable & $97(73.5)$ & $35(26.5)$ \\
Microbiology laboratory & Not applicable & $126(95.5)$ & $6(4.5)$ \\
Computed tomography & Not applicable & $125(94.7)$ & $7(5.3)$ \\
Magnetic resonance imaging & Not applicable & $109(82.5)$ & $23(17.4)$ \\
Cardiac catheterization laboratory & Not applicable & $117(88.6)$ & $15(11.4)$ \\
High-flow nasal cannula oxygen & $62(46.7)$ & Not applicable & $70(53.3)$ \\
Videolaryngoscope & $48(36.4)$ & Not applicable & $84(63.6)$ \\
Extracorporeal membrane oxygenation & $33(25)$ & $32(24.2)$ & $67(50.8)$ \\
\hline
\end{tabular}


Table 2: Characteristics of the participating intensive care units

\begin{tabular}{|c|c|c|c|c|c|}
\hline Characteristic & Number of ICUs (\%) & Number of patients (\%) & $\begin{array}{l}\text { APACHE I/ score } \\
(\text { mean } \pm S D)\end{array}$ & $\begin{array}{c}\text { ICU mortality (\%) } \\
\text { [terminal discharges, \%] }\end{array}$ & $\begin{array}{l}\text { Hospital mortality } \\
(n=4,594)\end{array}$ \\
\hline Overall & $132(100)$ & $4,669(100)$ & $16.7 \pm 9.8$ & $\begin{array}{r}1,092(23.4) \\
{[355,7.6 \%]}\end{array}$ & $1,164(25.3)$ \\
\hline \multicolumn{6}{|l|}{ Type of ICU } \\
\hline Open & $112(84.8)$ & $3,939(84.4)$ & $16.7 \pm 9.7$ & $\begin{array}{r}877(22.3) \\
{[274,7.0 \%]}\end{array}$ & $939(24.3)$ \\
\hline Closed & $20(15.2)$ & $730(15.6)$ & $16.8 \pm 10.0$ & $\begin{array}{l}215(29.5) \\
{[81,11.1 \%]}\end{array}$ & $225(31.0)$ \\
\hline$p$ & & & 0.884 & 0.000 & 0.0001 \\
\hline \multicolumn{6}{|l|}{ ICU specialty } \\
\hline 1. Mixed medical-surgical & $108(81.8)$ & $4,082(87.4)$ & $16.8 \pm 9.8^{*}$ & $\begin{array}{c}962(23.6) \\
{[304,7.4 \%]}\end{array}$ & $1,025(26.0)$ \\
\hline 2. All other specialcty ICUs & $24(18.2)$ & $587(12.6)$ & $16.6 \pm 9.3$ & $\begin{array}{l}130(22.1) \\
{[51,8.7 \%]}\end{array}$ & $139(23.7)$ \\
\hline a. Neuro-intensive care & $6(4.5)$ & $120(2.6)$ & $16.0 \pm 8.6$ & $\begin{array}{l}23(19.2) \\
{[18,15 \%]}\end{array}$ & $27(22.5)$ \\
\hline b. Surgical & $7(5.3)$ & $141(3.0)$ & $12.2 \pm 6.7$ & $\begin{array}{l}16(11.3) \\
{[2,1.4 \%]}\end{array}$ & $16(11.4)$ \\
\hline c. Coronary care & $1(0.8)$ & $45(0.96)$ & $11.8 \pm 6.7$ & $\begin{array}{c}5(11.1) \\
{[0]}\end{array}$ & $5(11.1)$ \\
\hline d. Medical & $8(6.1)$ & $266(5.7)$ & $19.6 \pm 9.9$ & $\begin{array}{c}84(31.6) \\
{[31,11.7 \%]}\end{array}$ & $88(33.3)$ \\
\hline e. Cardiac surgical & $1(0.8)$ & $5(0.11)$ & $16.2 \pm 6.3$ & $0(0)$ & $0(0)$ \\
\hline f. Other & $1(0.8)$ & $10(0.21)$ & $28.0 \pm 5.7$ & $\begin{array}{c}2(20.0) \\
{[0]}\end{array}$ & $3(30.0)$ \\
\hline$p$ & & & 0.7 (1 vs 2 ) & 0.45 (1 vs 2 ) & 0.11 (1 vs 2 ) \\
\hline \multicolumn{6}{|l|}{ Number of beds in ICU } \\
\hline A. $1-20$ beds & $67(50.8)$ & $1,490(31.9)$ & $17.1 \pm 9.6$ & $\begin{array}{r}349(23.4) \\
{[114,7.6 \%]}\end{array}$ & $380(25.5)$ \\
\hline B. $>20$ beds & $65(49.2)$ & $3,179(68.1)$ & $16.6 \pm 9.8$ & $\begin{array}{r}743(23.4) \\
{[241,7.6 \%]}\end{array}$ & $784(25.1)$ \\
\hline$p$ & & & 0.09 (A vs B) & 0.920 (A vs $B)$ & 0.20 (A vs $B)$ \\
\hline \multicolumn{6}{|l|}{ Number of hospital beds } \\
\hline A. $1-499$ & $84(63.6)$ & $2,453(52.5)$ & $17.1 \pm 9.8$ & $\begin{array}{c}521(21.2) \\
{[178,7.3 \%]}\end{array}$ & $560(22.3)$ \\
\hline a. $1-199$ & $32(24.2)$ & $777(16.6)$ & $15.4 \pm 9.6$ & $\begin{array}{l}169(21.8) \\
{[71,9.1 \%]}\end{array}$ & $190(24.7)$ \\
\hline b. $200-499$ & $52(39.4)$ & $1,676(35.9)$ & $17.8 \pm 9.8$ & $\begin{array}{c}352(21.0) \\
{[107,6.4 \%]}\end{array}$ & $370(22.5)$ \\
\hline B. $\geq 500$ & $48(36.4)$ & $2,216(47.5)$ & $16.4 \pm 9.7$ & $\begin{array}{c}571(25.8) \\
{[177,8.0 \%]}\end{array}$ & $604(27.7)$ \\
\hline$p$ & & & 0.01 (A vs $B$ ) & 0.000 (A vs $B)$ & 0.002 (A vs B) \\
\hline \multicolumn{6}{|l|}{ Nurse to patient ratio } \\
\hline $\begin{array}{c}<1: 2 \text { (less than } 1 \text { nurse per } \\
\text { two patients) }\end{array}$ & $45(34.1)$ & $1,205(25.8)$ & $16.8 \pm 9.6$ & $\begin{array}{c}265(21.2) \\
{[101,8.4 \%]}\end{array}$ & $289(24.1)$ \\
\hline $\begin{array}{l}\geq 1: 2 \text { ( } 1 \text { or more nurses per } \\
\text { two patients) }\end{array}$ & $87(65.9)$ & $3,464(74.2)$ & $16.7 \pm 9.8$ & $\begin{array}{c}827(23.9) \\
{[254,7.3 \%]}\end{array}$ & $874(25.7)$ \\
\hline$p$ & & & 0.672 & 0.182 & 0.278 \\
\hline \multicolumn{6}{|l|}{ Hospital } \\
\hline Public hospital ICUs & $6(4.5)$ & $111(2.4)$ & $18.6 \pm 11.1$ & $\begin{array}{l}31(27.9) \\
{[2,1.8 \%]}\end{array}$ & $33(30.0)$ \\
\hline Private hospital ICUs & $126(95.5)$ & $4,558(97.6)$ & $16.7 \pm 9.7$ & $\begin{array}{c}1,061(23.3) \\
{[353,7.7 \%]}\end{array}$ & $1,131(25.2)$ \\
\hline$p$ & 0 & 0 & 0.04 & 0.253 & 0.255 \\
\hline
\end{tabular}




\begin{tabular}{|c|c|c|c|c|c|}
\hline \multicolumn{6}{|c|}{ Postgraduate teaching/training program in intensive care } \\
\hline None & $37(28.0)$ & $812(17.4)$ & $15.9 \pm 9.5$ & $\begin{array}{l}168(20.7) \\
{[60,7.4 \%]}\end{array}$ & $186(23.8)$ \\
\hline Present & $95(72.0)$ & $3,857(82.6)$ & $16.9 \pm 9.8$ & $\begin{array}{c}924(23.9) \\
{[295,7.6 \%]}\end{array}$ & $978(25.7)$ \\
\hline$p$ & & & 0.006 & 0.046 & 0.264 \\
\hline \multicolumn{6}{|c|}{ Equipment and facilities } \\
\hline Adequate & $62(47.0)$ & $2,855(61.1)$ & $17.2 \pm 9.9$ & $\begin{array}{c}692(24.2) \\
{[229,8.0 \%]}\end{array}$ & $738(26.3)$ \\
\hline Not adequate & $70(53.0)$ & $1,814(38.9)$ & $16.0 \pm 9.4$ & $\begin{array}{c}400(22.1) \\
{[126,6.9 \%]}\end{array}$ & $426(23.8)$ \\
\hline$p$ & & & 0.004 & 0.089 & 0.055 \\
\hline \multicolumn{6}{|c|}{$\mathrm{NABH} / \mathrm{JCl}$ accreditation } \\
\hline Not accredited & $109(82.6)$ & 4,136 & $16.5 \pm 9.7$ & $\begin{array}{c}965(23.3) \\
{[304,7.4 \%]}\end{array}$ & $1,023(25.2)$ \\
\hline Accredited & $23(17.4)$ & 533 & $18.3 \pm 10.2$ & $\begin{array}{l}127(23.8) \\
{[51,9.6 \%]}\end{array}$ & $141(26.6)$ \\
\hline$p$ & & & 0.000 & 0.748 & 0.846 \\
\hline \multicolumn{6}{|c|}{ Written protocols } \\
\hline Present & $122(92.4)$ & 4,486 & $16.8 \pm 9.8$ & $\begin{array}{c}1,051(23.4) \\
{[338,7.5 \%]}\end{array}$ & $1,119(25.4)$ \\
\hline Absent & $10(7.6)$ & 183 & $15.4 \pm 9.0$ & $\begin{array}{c}41(22.4) \\
{[17,9.3 \%]}\end{array}$ & $45(24.7)$ \\
\hline$p$ & & & 0.059 & 0.748 & 0.846 \\
\hline
\end{tabular}

positive laboratory test for dengue, 78 (1.67\%) for H1N1 influenza virus, one for cytomegalovirus, three for other viruses, 23 (0.49\%) for scrub typhus, 18 (0.39\%) for leptospirosis, and 14 (0.30\%) patients for malaria.

On the study day, 3,263 patients (69.9\%) received antimicrobials. In patients receiving antimicrobials, a median of 2.0 (IQR 1, 2) antimicrobials was given, and $16.5 \%$ of patients received three or more antimicrobials and 68 patients (1.5\%) were admitted after poisoning or drug overdose, including 36 organophosphorus or organochlorine poisoning, 9 corrosive poisonings, and 4 snake bites. ICU mortality in this group was $19.1 \%$.

Various interventions in the ICU are detailed in Table 5. Patients receiving invasive $M V$, VIs, and RRT had significantly higher mortality than those who did not ( 44.4 vs $16.7 \%, p<0.001 ; 44.0$ vs $17.5 \%, p<0.001$; and 41.7 vs $21.5 \%, p<0.001$, respectively). Arterial and central venous catheters were inserted in 25.4 and $34.3 \%$ of all patients, respectively, and 50.3 and $64.3 \%$ of 1,033 patients receiving VIs. Echocardiography in the ICU was performed in $21.4 \%$ of patients, and cardiac output was measured in 81 patients (1.7\%). In 727 patients who received fluid boluses, normal saline was used in more than $86 \%$ of patients, balanced crystalloids were used in $58.4 \%$, and album in $6.6 \%$ of patients.

The degree of compliance with selected process measures is outlined in Table 6. Almost all ICUs (92\%) had written protocols. Compliance for process measures related to MV ranged from 62.7$85.3 \%$, whereas for monitoring delirium, sedation, and analgesia, it ranged from $11.2-47.4 \%$. Inappropriate triggers for transfusion of blood products, based only on the laboratory values $(\mathrm{Hb}>9 \mathrm{~g} / \mathrm{dL})$, were observed in $7.7-25.3 \%$ of patients (Table 6).
The results of the multivariable analysis of organizational and patient characteristics, severity of illness, and need for interventions are summarized in Table 7. Closed ICUs and ICUs in hospitals with $\geq 500$ beds were independently associated with increased ICU mortality. In addition, the APACHE II and SOFA scores on the study day, medical admissions, the presence of cancer or cirrhosis of the liver, the presence of infection on the study day, and the need for invasive or noninvasive ventilation or VIs were independent predictors of mortality.

\section{Discussion}

The study provides a snapshot of adult critical care in India between August 2018 and May 2019. Patients had moderate severity of illness and the ICU mortality, including TDs, was $23.4 \%$.

While we attempted to describe the change in intensive care practices and outcomes over the 9 years between INDICAPS and INDICAPS-II (Table 8), direct comparisons of the results of the two studies may not be appropriate. The participating ICUs were different; ICUs that participated in both studies may have changed in their structure, organization, and staffing in the intervening period, and criteria used to classify open and closed ICUs, adequately equipped ICUs, sepsis, and tropical infections differed between the two studies.

Overall ICU mortality of $23.4 \%$ appears to be higher than the $18.1 \%$ mortality observed in the previous study. The proportion of patients dying in the ICU was $15.8 \%$, and TDs constituted a significant percentage of total nonsurvivors (32.5\%) in the present study, as compared to $25.1 \%$ in INDICAPS. The increase in the 
Table 3: Primary reason for ICU admission

\begin{tabular}{|c|c|c|c|}
\hline $\begin{array}{l}\text { Primary reason for ICU } \\
\text { admission }\end{array}$ & $\begin{array}{l}\text { Number of } \\
\text { patients }\end{array}$ & $\begin{array}{l}\text { APACHE II } \\
\text { score }\end{array}$ & $\begin{array}{c}\text { ICU nonsurvivors } \\
N(\%)\end{array}$ \\
\hline Medical & 3,993 & $17.9 \pm 9.4^{*}$ & $1,030(25.8)^{*}$ \\
\hline Cardiovascular & 580 & $15.2 \pm 9.4$ & $105(18.1)$ \\
\hline Respiratory & 884 & $19.6 \pm 8.9$ & $260(29.4)$ \\
\hline Gastrointestinal & 462 & $17.5 \pm 9.0$ & $146(31.6)$ \\
\hline Neurological & 723 & $16.3 \pm 8.8$ & $163(22.5)$ \\
\hline Sepsis & 587 & $20.7 \pm 9.4$ & $202(34.4)$ \\
\hline Trauma & 205 & $13.9 \pm 8.8$ & $31(15.1)$ \\
\hline Metabolic & 123 & $17.2 \pm 9.7$ & $21(17.1)$ \\
\hline Hematological & 84 & $16.5 \pm 9.3$ & $20(23.8)$ \\
\hline Renal & 247 & $22.2 \pm 8.9$ & $59(23.9)$ \\
\hline Unclassified & 100 & $14.1 \pm 9.3$ & $23(23.0)$ \\
\hline Surgical & 676 & $11.5 \pm 6.5$ & $62(9.2)$ \\
\hline Cardiovascular & 126 & $10.3 \pm 5.2$ & $4(3.2)$ \\
\hline Respiratory & 63 & $13.1 \pm 7.7$ & $8(12.7)$ \\
\hline Gastrointestinal & 187 & $11.5 \pm 5.7$ & $19(10.2)$ \\
\hline Neurological & 113 & $12.0 \pm 7.9$ & $16(14.2)$ \\
\hline Trauma & 34 & $12.2 \pm 7.5$ & $7(20.6)$ \\
\hline Renal & 58 & $11.8 \pm 6.4$ & $4(6.9)$ \\
\hline Obstetric & 44 & $10.5 \pm 5.2$ & $1(2.3)$ \\
\hline $\begin{array}{l}\text { Hip or extremity } \\
\text { fracture }\end{array}$ & 46 & $11.4 \pm 6.3$ & $3(6.5)$ \\
\hline Unclassified & 3 & $12.0 \pm 7.9$ & $0(0)$ \\
\hline \multicolumn{4}{|l|}{ Type of Surgery } \\
\hline Elective surgery & 462 & $10.8 \pm 6.0$ & $37(8.0)^{*}$ \\
\hline Emergency surgery & 214 & $12.3 \pm 7.9$ & $25(11.7)$ \\
\hline
\end{tabular}

proportion of TDs is an area of concern and may reflect more defensive practice after the Aruna Shanbaugh case, where the Supreme Court ruled that "passive euthanasia" was permissible, but required prior approval from the High Court. ${ }^{8}$ We assumed that all TDs from the ICU eventually died. A single-center study from a tertiary level private hospital in South India found that 23 and $14 \%$ of patients were alive 30 and 90 days after being discharged against medical advice, respectively. However, only $9 \%$ of their patients were discharged because of an overall poor prognosis. ${ }^{9}$ Thus classifying all TDs does overestimate mortality, but excluding them would grossly underestimate mortality.

Public hospital ICUs, self-paying patients, and inadequately equipped ICUs were independently associated with ICU mortality in INDICAPS but were not associated with ICU mortality in INDICAPS-II on univariate analysis. Only six (4.5\%) public hospital ICUs accounting for 111 (2.4\%) patients participated in the study. The proportion of self-paying patients was smaller in this study as compared to INDICAPS (64.5 vs $80.5 \%){ }^{1}$ This may be the result of increasing penetration of insurance as well as central and state government schemes. While $53.0 \%$ of ICUs were inadequately equipped in this study, as opposed to only $32.5 \%$ in the INDICAPS study, this may be because we changed the definition of adequately equipped ICUs to include the presence of a blood bank in the hospital and have facilities for RRT and echocardiography in the ICU, rather than in the ICU or hospital. While there was a median of 0.55 invasive ventilators per ICU bed, HFNO capability was available in only $47 \%$ of ICUs.

In INDICAPS, we found no difference in outcome between open and closed ICUs, where an open ICU was defined as one in which care of the patient was directed by non-ICU doctor teams, and orders could be written by non-ICU team doctors. ${ }^{1}$ A striking finding in INDICAPS-II was the association of closed ICUs with higher mortality on multivariable analysis. A closed ICU was defined as one in which final orders for the patient

Table 4: Patient demographics, ICU admission characteristics and severity of illness*

\begin{tabular}{|c|c|c|c|c|}
\hline & All patients & ICU survivors & ICU nonsurvivors & $p$ \\
\hline \multicolumn{5}{|l|}{ Patient demographics } \\
\hline Number of patients (\%) & $4,669(100)$ & $3,577(76.6 \%)$ & $1,092(23.4 \%)$ & \\
\hline Age (years) (mean $\pm S D)$ & $56.9 \pm 17.4$ & $56.4 \pm 17.6$ & $58.5 \pm 16.6$ & 0.01 \\
\hline Male [number of patients, (\%)] & $2,973(63.7)$ & $2,271(76.4)$ & $702(23.6)$ & 0.632 \\
\hline Female [number of patients, (\%)] & $1,696(36.3)$ & $1,306(77.0)$ & $390(23.0)$ & \\
\hline Financial resources & & & & 0.193 \\
\hline Self-paying [number of patients, (\%)] & $3,010(64.5)$ & $2,288(76.0)$ & $722(24.0)$ & \\
\hline Not self-paying (payment by employer, insurance, etc.) [number of patients, (\%)] & $1,659(35.5)$ & $1,289(77.7)$ & $370(22.3)$ & \\
\hline Type of ICU admission [number of patients, (\%)] & & & & $<0.001$ \\
\hline Medical/nonoperative & $3,993(85.5)$ & $2,963(74.2)$ & $1,030(25.8)$ & \\
\hline Surgical & $676(14.5)$ & $614(90.8)$ & $62(9.2)$ & \\
\hline Elective postoperative & $462(9.9)$ & $425(92.0)$ & $37(8.0)$ & \\
\hline Unscheduled/emergent postoperative & $214(4.6)$ & $189(88.3)$ & $25(11.7)$ & \\
\hline Source of admission [number of patients, (\%)] & & & & $<0.001$ \\
\hline Home & $913(19.6)$ & $716(78.4)$ & $197(21.6)$ & \\
\hline Emergency department & $1,596(34.2)$ & $1,202(75.3)$ & $394(24.7)$ & \\
\hline Ward of same hospital & $703(15.1)$ & $479(68.1)$ & $224(31.9)$ & \\
\hline ICU of other hospital & $435(9.3)$ & $307(70.6)$ & $128(29.4)$ & \\
\hline Ward of other hospital & $283(6.1)$ & $212(74.9)$ & $71(25.1)$ & \\
\hline
\end{tabular}


Intensive Care in India: INDICAPS-II

\begin{tabular}{|c|c|c|c|c|}
\hline From operation theater & $676(14.5)$ & $614(90.8)$ & $62(9.2)$ & \\
\hline Not known/missing & $63(1.3)$ & $47(74.6)$ & $16(25.4)$ & \\
\hline \multicolumn{5}{|l|}{ Comorbidities [number of patients, (\%)] } \\
\hline Chronic obstructive pulmonary disease & $363(7.8)$ & 267 (73.6) & $96(26.4)$ & 0.152 \\
\hline Diabetes mellitus (IDDM and NIDDM) & $1,555(33.3)$ & $1,170(77.3)$ & $385(22.7)$ & 0.118 \\
\hline Hypertension & $2,055(44.0)$ & $1,589(77.3)$ & $466(22.7)$ & 0.308 \\
\hline Heart failure & $362(7.8)$ & $245(67.7)$ & $117(32.3)$ & $<0.001$ \\
\hline Any cancer & $598(12.8)$ & $417(69.7)$ & $181(30.3)$ & $<0.001$ \\
\hline Hematological malignancy & $80(1.7)$ & $41(51.3)$ & $39(48.7)$ & $<0.001$ \\
\hline Metastatic cancer & $200(4.3)$ & $118(59.0)$ & $82(41.0)$ & $<0.001$ \\
\hline Dialysis-dependent renal failure & $280(6.0)$ & 179 (63.9) & $101(36.1)$ & 0.001 \\
\hline Cirrhosis of the liver & $195(4.2)$ & $102(52.3)$ & $93(47.7)$ & $<0.001$ \\
\hline Immunosuppressive treatment & $354(7.6)$ & $237(66.9)$ & $117(33.1)$ & 0.001 \\
\hline Number of comorbidities [number of patients, (\%)] & & & & $<0.001$ \\
\hline 0 & $1,496(32.0)$ & $1,203(80.4)$ & $293(19.6)$ & \\
\hline 1 & $1,364(29.2)$ & $1,049(76.9)$ & $315(23.1)$ & \\
\hline 2 & $1,186(25.4)$ & $912(76.9)$ & $214(23.1)$ & \\
\hline 3 & $483(10.3)$ & $325(67.3)$ & $158(32.7)$ & \\
\hline 4 & $125(2.7)$ & $83(66.4)$ & $42(33.6)$ & \\
\hline 5 & $13(0.3)$ & $4(30.8)$ & $9(69.2)$ & \\
\hline 6 & $2(0.0)$ & $1(50.0)$ & $1(50.0)$ & \\
\hline Patients with suspected or confirmed infection on the study day & $1,195(25.6)$ & 740 (61.9) & $455(38.1)$ & $<0.001$ \\
\hline Patients in whom infection developed during the ICU stay & $121(2.6)$ & $68(56.2)$ & $53(43.8)$ & $<0.001$ \\
\hline Sepsis and/or septic shock during ICU stay & $1,368(29.3)$ & $863(63.1)$ & 505 (36.9) & $<0.001$ \\
\hline Septic shock during ICU stay & $590(12.6)$ & $275(46.6)$ & $315(53.4)$ & $<0.001$ \\
\hline Confirmed tropical infection & $135(2.9)$ & $110(81.5)$ & $25(18.5)$ & 0.175 \\
\hline Acute respiratory failure with $\mathrm{PaO}_{2} / \mathrm{FiO}_{2}$ ratio $<300$ & $2,395(51.3)$ & $1,661(69.4)$ & $734(30.6)$ & $<0.001$ \\
\hline Poisoning or overdose & $68(1.5)$ & $55(81.9)$ & $13(19.1)$ & 0.54 \\
\hline \multicolumn{5}{|l|}{ Severity of illness } \\
\hline APACHE II score (mean \pm SD) & $16.7 \pm 9.8$ & $14.8 \pm 8.6$ & $23.1 \pm 10.5$ & $<0.001$ \\
\hline SOFA score (mean \pm SD) & $4.4 \pm 3.6$ & $3.7 \pm 3.2$ & $6.7 \pm 4.1$ & $<0.001$ \\
\hline No. of organ failures [median, (IQR)] & $0[0-1]$ & $0[0-1]$ & $1[0-2]$ & $<0.001$ \\
\hline $\begin{array}{l}\text { ICU stay, days [median, (IQR)] } \\
N=4,137\end{array}$ & $6[3-13]$ & $6[3-12]$ & 9 [4-17] & $<0.001$ \\
\hline $\begin{array}{l}\text { Hospital stay, days [median, (IQR)] } \\
N=3,842\end{array}$ & 12 [7-20] & $12[7-20]$ & $12[6-21]$ & 0.225 \\
\hline ICU admission to study day interval, days [median, (IQR)] & $2.0[1-6]$ & $2.0[1-5]$ & $3.0[1-8]$ & $<0.001$ \\
\hline
\end{tabular}

Figures represent the number of patients (percent) unless otherwise indicated; $p$ values compare survivors vs nonsurvivors; ICU, intensive care unit; IDDM, insulin-dependent diabetes mellitus; NIDDM, non-insulin-dependent diabetes mellitus; APACHE, acute physiology and chronic health evaluation; SOFA, sequential organ failure assessment; IQR, interquartile range

were written only by the ICU team; all other ICUs, where orders could be written by either the ICU team or the primary team, were considered as open ICUs. Thus an open ICU could include not only those ICUs where the care of the patient was directed by non-ICU teams but also the "hybrid" or mandatory consult model, where all patients admitted to the ICU are seen by the intensive care team as well as by the primary consultant, both of them have the privileges to write orders. ${ }^{10-12}$ An overwhelming majority of ICUs (84.8\%) were classified as open ICUs. Since the data in this study were contributed by intensivists, we believe that most open ICUs followed a "hybrid" model, which may have resulted in better interaction between the ICU and primary referring teams, with a beneficial impact on the outcome. ${ }^{13}$ Two other surveys of Indian ICUs in 2018 found that only 20 and 14\% were closed ICUs. However, they did not evaluate association with mortality. ${ }^{14,15}$ A study based on the Project IMPACT database of $1,01,832$ patients in 123 ICUs in the United States had also found that even after adjusting for disease severity, patients managed by critical care specialists showed higher mortality. ${ }^{16}$ They speculated that some routine critical care practices and procedures may not be beneficial or that the presence of confounders not included in the model may account for worse outcomes. Another study of 69 ICUs in the USA found higher crude mortality (but no difference in adjusted mortality) for closed ICUs compared to open ICUs, ${ }^{13}$ while an analysis of data from the EPIC study found no difference in outcome between closed and open ICUs. ${ }^{17}$ Unlike these studies, ${ }^{13,17}$ we did not find a higher nurse: patient ratio to be associated with a better 

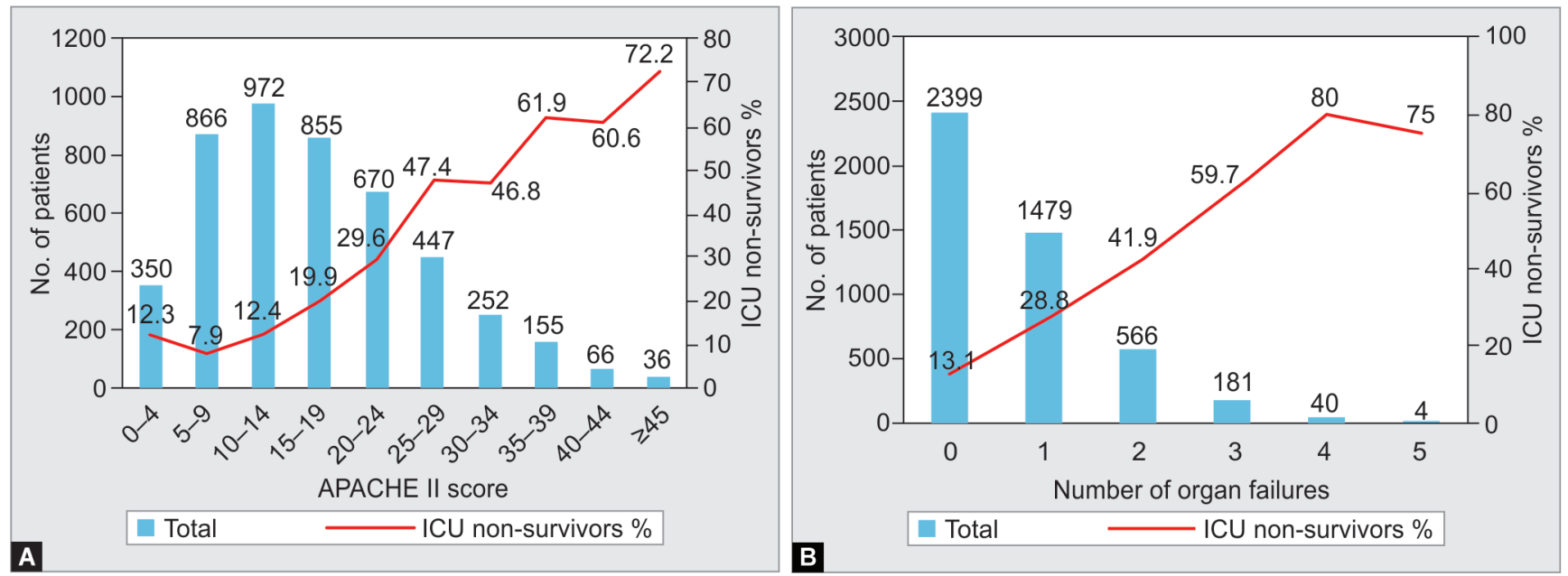

Figs $1 \mathrm{~A}$ and B: (A) APACHE II score on the study day; (B) Number of organ failures on the study day and ICU nonsurvivors

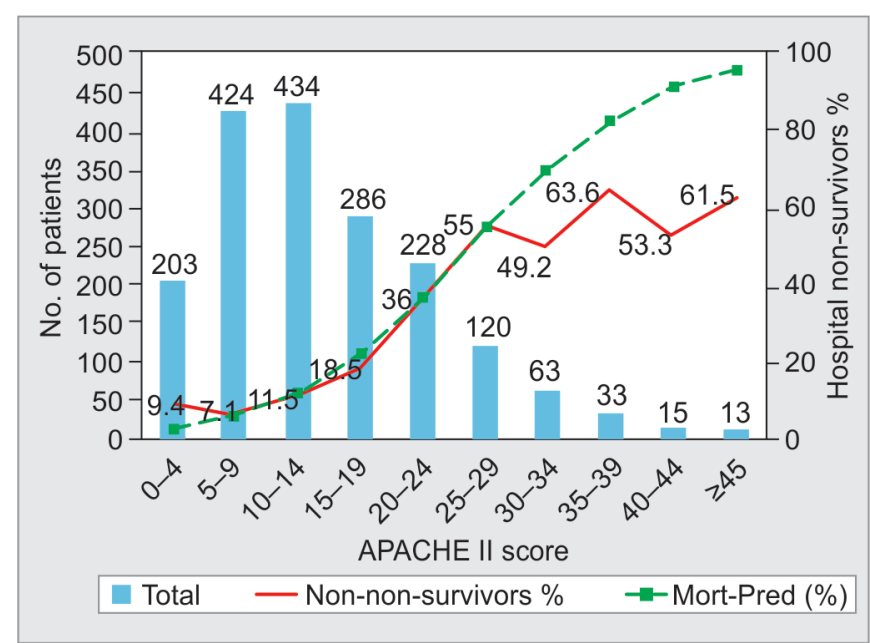

Fig. 2: Predicted vs actual hospital mortality for 1,819 patients

outcome. We believe that further studies specifically directed at practice patterns in open and closed ICUs are required, and a separate analysis of the hybrid model needs to be performed.

The SMR observed was 0.92 , higher than the 0.68 observed in INDICAPS. However, this was obtained in a subset of patients admitted within 24 hours of a study day. A formal evaluation of APACHE II, as well as other scoring systems, is necessary.

This study confirms that gram-negative infections are predominant in India (75.6\%), much higher than in Western countries. ${ }^{18}$ The ICU mortality in patients with sepsis (including septic shock) was higher than that in INDICAPS, but criteria for identifying sepsis were different; in INDICAPS, the diagnosis of sepsis was at the discretion of the investigator. ${ }^{1}$ Compared to INDICAPS, fewer patients received MV and RRT and a similar proportion received VIs; however, ICU mortality in patients receiving these interventions was higher compared to INDICAPS (Table 8).

We looked at select process measures in patients who received invasive $\mathrm{MV}$. Less than $80 \%$ compliance was observed with most, except stress ulcer prophylaxis. In particular, monitoring for delirium and sedation was done in less than $20 \%$ of patients, while pain assessment was performed in less than half of the patients. Despite the findings of the National Audit Project-4 that failure to use capnography contributed to $74 \%$ of cases of death or persistent neurological injury related to airway management in the ICU or emergency department, ${ }^{19}$ capnography was routinely used after intubation in less than $35 \%$ of ICUs. Triggers for transfusion of RBCs, FFP, and platelets appeared to be inappropriate in up to $25.3 \%$ of patients. However, this determination was based only on laboratory parameters; data on clinical circumstances that may have necessitated transfusions, e.g., ongoing hemorrhage and perioperative or periprocedural transfusion, were not available. Thus, further improvements are required in the organization and delivery of critical care in Indian ICUs.

There are limitations to our study. Participation was purely voluntary, and ICUs that were motivated and willing to share data contributed to the study. Participation of public hospital ICUs was negligible, and only $14.5 \%$ of patients were surgical admissions. These are even lower than in INDICAPS. ' Source data verification was not performed.

The strengths of this study include a large number of ICUs and patients from all regions of the country and different types of ICUs. Updated definitions were used to classify patients with sepsis, and tropical infections were diagnosed based on confirmatory laboratory tests. Data from this study can be used as a benchmark of structure, process, and outcome of Indian ICUs for comparative, quality assurance, and audit purposes. This may also help the regulatory and planning authorities for resource allocation and also in planning future research studies. Future studies could focus on details of ICU organization, costs of care, and antibiotic utilization.

\section{Conclusion}

Patients in this study had moderate severity of illness with relatively high mortality in patients with sepsis, patients on VIs, or receiving MV. Closed ICUs were independently associated with a worse outcome, and the proportion of TDs from the ICU has increased compared to INDICAPS. Public hospital ICUs, self-paying patients, and inadequately equipped ICUs were not associated 
Intensive Care in India: INDICAPS-II

Table 5: Interventions

\begin{tabular}{|c|c|c|c|c|}
\hline & All patients & ICU survivors & ICU nonsurvivors (mortality \%) & $p$ \\
\hline Number of patients & $4,669(100)$ & $3,577(76.6)$ & $1,092(23.4)$ & \\
\hline \multicolumn{5}{|l|}{ Infectious disease } \\
\hline Patients receiving antibiotics & $3,263(69.9)$ & $2,417(74.1)$ & $846(25.9)$ & $<0.001$ \\
\hline One antibiotic & $1,321(28.3)$ & $1,084(82.1)$ & $237(17.9)$ & \\
\hline Two antibiotics & $1,172(25.1)$ & $861(73.5)$ & $311(26.5)$ & \\
\hline Three antibiotics & $527(11.3)$ & $344(65.3)$ & $183(34.7)$ & \\
\hline Four or more antibiotics & $243(5.2)$ & $128(52.7)$ & $115(47.3)$ & \\
\hline Procalcitonin measured & $528(11.3)$ & $352(66.7)$ & $176(33.3)$ & $<0.001$ \\
\hline \multicolumn{5}{|l|}{ Ventilation and airway } \\
\hline High-flow nasal oxygen & $165(3.5)$ & $110(66.7)$ & $55(33.3)$ & $<0.001$ \\
\hline Mechanical ventilation & $1,539(33.0)$ & $974(7.2)$ & $635(58.2)$ & $<0.001$ \\
\hline Noninvasive ventilation & $484(10.4)$ & $349(72.1)$ & $135(27.9)$ & $<0.001$ \\
\hline Invasive ventilation & $1,125(24.1)$ & $625(55.6)$ & $500(44.4)$ & $<0.001$ \\
\hline Prone position & $175(3.7)$ & $114(65.1)$ & $61(34.9)$ & 0.001 \\
\hline Neuromuscular blockade & $272(5.8)$ & $147(54.0)$ & $125(46.0)$ & $<0.001$ \\
\hline Tracheal intubation & $1,006(21.5)$ & $552(54.9)$ & $454(41.1)$ & $<0.001$ \\
\hline Tracheostomy & $392(8.4)$ & $274(69.9)$ & $118(30.1)$ & 0.02 \\
\hline Surgical tracheostomy & $201(4.3)$ & $139(69.2)$ & $62(30.8)$ & \\
\hline Percutaneous tracheostomy & $191(4.1)$ & $135(70.7)$ & $56(29.3)$ & \\
\hline High-frequency oscillation & $40(0.9)$ & $25(62.5)$ & $15(37.5)$ & 0.03 \\
\hline Extracorporeal membrane oxygenation (veno-venous) & $20(0.4)$ & $19(95.0)$ & $1(5.0)$ & \\
\hline Extracorporeal membrane oxygenation (veno-arterial) & $4(0.1)$ & $3(75.0)$ & $1(25.0)$ & \\
\hline Capnography & $432(9.1)$ & $276(63.9)$ & $156(36.1)$ & $<0.001$ \\
\hline \multicolumn{5}{|l|}{ Renal } \\
\hline Renal replacement therapy & $434(9.3)$ & $253(58.3)$ & $181(41.7)$ & $<0.001$ \\
\hline Continuous & $34(0.7)$ & $18(52.9)$ & $16(47.1)$ & \\
\hline Intermittent hemodialysis & $177(3.8)$ & $117(66.1)$ & $60(33.9)$ & \\
\hline Sustained low-efficiency daily dialysis & $187(4.0)$ & $96(51.3)$ & $91(48.7)$ & \\
\hline Ultrafiltration & $17(0.4)$ & $11(64.7)$ & $6(35.3)$ & \\
\hline \multicolumn{5}{|l|}{ Cardiovascular and hemodynamic } \\
\hline Vasopressors/inotropes & $898(22.2)$ & $574(63.9)$ & $324(36.1)$ & $<0.001$ \\
\hline Invasive blood pressure monitoring & $1,185(25.4)$ & $751(63.4)$ & $434(36.6)$ & $<0.001$ \\
\hline Central venous catheter inserted & $1,603(34.3)$ & $1,048(65.4)$ & $555(34.6)$ & $<0.001$ \\
\hline Central venous pressure monitoring & $566(12.1)$ & $398(70.3)$ & $168(29.7)$ & $<0.001$ \\
\hline Hourly urine output monitoring & $3,253(69.7)$ & $2,412(74.1)$ & $841(25.9)$ & $<0.001$ \\
\hline Echocardiography in ICU & $1,000(21.4)$ & $674(67.4)$ & $326(32.6)$ & $<0.001$ \\
\hline Pulse pressure variation monitoring & $279(6.0)$ & $186(66.7)$ & $93(33.3)$ & $<0.001$ \\
\hline Cardiac output monitoring & $81(1.7)$ & $61(75.3)$ & $20(24.7)$ & 0.30 \\
\hline Passive leg raising test & $108(2.3)$ & $72(66.7)$ & $36(33.3)$ & $<0.001$ \\
\hline Blood lactate measured & $1,477(31.6)$ & $952(64.5)$ & $525(35.5)$ & $<0.001$ \\
\hline $\mathrm{ScvO}_{2}$ measured & $69(1.5)$ & $41(59.4)$ & $28(40.6)$ & 0.002 \\
\hline Intra-aortic balloon pump & $76(1.6)$ & $46(60.5)$ & $30(39.5)$ & 0.001 \\
\hline \multicolumn{5}{|l|}{ Fluid therapy, blood and blood products } \\
\hline Fluid boluses & $727(15.6)$ & $503(69.2)$ & $224(30.8)$ & $<0.001$ \\
\hline Normal saline & $627(13.4)$ & $4,426(70.5)$ & $185(29.5)$ & $<0.001$ \\
\hline Lactated Ringers' & $215(4.6)$ & $161(74.9)$ & $54(25.1)$ & 0.18 \\
\hline Plasmalyte ${ }^{\mathrm{TM}}$ & $210(4.5)$ & $143(68.1)$ & $67(31.9)$ & 0.002 \\
\hline Gelatins & $25(0.5)$ & $20(80.0)$ & $5(20.0)$ & 0.27 \\
\hline Starches & $18(0.4)$ & $15(83.3)$ & $3(16.7)$ & 0.37 \\
\hline Albumin & $48(1.0)$ & $33(68.8)$ & $15(31.2)$ & 0.06 \\
\hline Whole blood/packed red blood cells & $297(6.4)$ & $200(67.3)$ & $97(32.7)$ & $<0.001$ \\
\hline
\end{tabular}


Table 5: (Contd...)

\begin{tabular}{|c|c|c|c|c|}
\hline & All patients & ICU survivors & ICU nonsurvivors (mortality \%) & $p$ \\
\hline Fresh frozen plasma & $99(2.1)$ & $45(45.5)$ & $54(54.5)$ & $<0.001$ \\
\hline Platelets & $76(1.6)$ & $37(48.7)$ & $39(51.3)$ & $<0.001$ \\
\hline Random donor platelets & $38(0.8)$ & $17(44.7)$ & $21(55.3)$ & \\
\hline Single donor platelets & $38(0.8)$ & $20(52.6)$ & $18(47.4)$ & \\
\hline \multicolumn{5}{|l|}{ Neurological } \\
\hline Intracranial pressure monitoring & $25(0.5)$ & $14(56.0)$ & $11(44.0)$ & $<0.001$ \\
\hline EEG monitoring & $147(3.1)$ & $114(77.6)$ & $33(22.4)$ & 0.004 \\
\hline Transcranial Doppler & $32(0.7)$ & $22(68.8)$ & $10(31.2)$ & 0.006 \\
\hline \multicolumn{5}{|l|}{ General care } \\
\hline Stress ulcer prophylaxis & $3,635(90.0)$ & 2,953 (89.2) & $682(93.6)$ & $<0.001$ \\
\hline Low-molecular-weight heparin for deep venous thrombosis prophylaxis & $1,384(29.6)$ & $1,060(76.6)$ & $324(23.4)$ & 0.25 \\
\hline Unfractionated heparin & $365(7.8)$ & $266(72.9)$ & $99(27.1)$ & 0.10 \\
\hline Compression stockings & $547(11.7)$ & $414(75.7)$ & $133(24.3)$ & 0.30 \\
\hline Intermittent calf compression & $1,175(25.2)$ & $836(71.1)$ & $339(28.9)$ & $<0.001$ \\
\hline Enteral nutrition & $2,823(60.5)$ & 2,085 (73.9) & $738(26.1)$ & $<0.001$ \\
\hline Parenteral nutrition & $230(4.9)$ & $152(66.1)$ & $78(33.9)$ & $<0.001$ \\
\hline \multicolumn{5}{|l|}{ Sedation, analgesia, delirium } \\
\hline Sedation measured & $800(17.1)$ & $519(64.9)$ & $281(35.1)$ & $<0.001$ \\
\hline Ramsay sedation score & $228(4.9)$ & $172(75.4)$ & $56(24.6)$ & \\
\hline RASS & $592(12.7)$ & $369(62.3)$ & $223(37.7)$ & \\
\hline Bispectral index & $88(1.9)$ & $54(61.4)$ & $34(38.6)$ & \\
\hline Pain measured & $2,215(47.4)$ & $1,703(76.9)$ & $512(23.1)$ & 0.36 \\
\hline Behavioral pain scale & $373(8.0)$ & $249(66.8)$ & $124(33.2)$ & \\
\hline Critical care pain observation tool & $200(4.3)$ & $141(70.5)$ & $59(29.5)$ & \\
\hline Numeric rating scale & $242(5.2)$ & $199(82.2)$ & $43(17.8)$ & \\
\hline Visual analog scale & $1,244(26.6)$ & $979(78.7)$ & $265(21.3)$ & \\
\hline Delirium monitored & $522(11.2)$ & $397(76.1)$ & $125(23.9)$ & 0.27 \\
\hline CAM-ICU & $500(10.7)$ & $379(75.8)$ & $121(24.2)$ & \\
\hline IDSC & $11(0.2)$ & $10(90.9)$ & $1(9.1)$ & \\
\hline
\end{tabular}

$\mathrm{ICU}$, intensive care unit; RASS, Richmond agitation-sedation scale; CAM, confusion assessment method; IDSC, intensive care delirium screening checklist

Table 6: Compliance with process measures

\begin{tabular}{lc}
\hline Indicator & Compliance \\
\hline ICUs having written protocols & $122(92.4 \%)$ \\
ICUs that always use capnography to confirm & $46(34.8 \%)$ \\
tracheal intubation & \\
Patents receiving invasive mechanical ventilation & 1,055 \\
$\quad$ Subglottic suction via endotracheal or & $814(77.2 \%)$ \\
tracheostomy tube & \\
Closed tracheal suction system & $661(62.7 \%)$ \\
Receiving DVT prophylaxis & $807(76.5 \%)$ \\
Receiving stress ulcer prophylaxis & $900(85.3 \%)$ \\
Patients with plateau pressure $<30 ~ \mathrm{~cm} \mathrm{H}_{2} \mathrm{O}^{*}$ & $750(71.1)$ \\
Sedation monitored & $800(17.1)$ \\
Analgesia monitored & $2,215(47.4 \%)$ \\
Delirium monitored & $522(11.2)$ \\
Patients receiving packed red blood cell & 297 \\
transfusion & \\
Hb (g/dL) at transfusion [Median, (IQR)] & $7.0[6.2-7.9]$ \\
$N=265$ & \\
Patients with Hb $>9$ g/dL & $23(7.7 \%)$ \\
\hline
\end{tabular}

\begin{tabular}{lc}
\hline Indicator & Compliance \\
\hline Patients receiving fresh frozen plasma & 99 \\
INR at transfusion [Median, (IQR)] $N=92$ & $2.25[1.67-3.43]$ \\
APTT at transfusion [Median, (IQR)] N=92 & $42.85[33.85-58.5]$ \\
Patients with INR $\leq 1.5$ and APPT $\leq 45^{* *}$ & $25(25.3 \%)$ \\
Patients receiving platelet transfusions & 76 \\
Platelet count at transfusion (median, [IQR]) & $18.0[8.63-40]$
\end{tabular}
$(N=72)$

Patients with platelet count $>50 \times 10^{3} / \mathrm{mm}^{3 * *} \quad 14(19.4 \%)$

$\mathrm{ICU}$, intensive care unit; DVT, deep venous thrombosis; $\mathrm{Hb}$, hemoglobin; $\mathrm{IQR}$, interquartile range; INR, international normalized ratio; APTT, activated partial thromboplastin time; "Plateau pressure during volume-controlled ventilation, peak airway pressure during pressure-controlled ventilation; ** Inappropriate use of blood product based on the laboratory values; the clinical context was not available

with increased ICU mortality. Analgesia, sedation, and delirium are infrequently monitored, and the use of capnography after tracheal intubation is uncommon, suggesting scope for improvements in 
Table 7: Multivariable analysis for independent predictors of mortality

\begin{tabular}{lclll}
\hline & $p$ & $\begin{array}{l}\text { Odds ratio for } \\
\text { ICU mortality }\end{array}$ & $\begin{array}{l}95 \% \mathrm{Cl} \\
\text { (lower) }\end{array}$ & $\begin{array}{l}95 \% \mathrm{Cl} \\
\text { (upper) }\end{array}$ \\
\hline $\begin{array}{l}\text { Biopsy-proven cirrhosis } \\
\text { Medical admission (vs }\end{array}$ & 0.000 & 2.523 & 1.815 & 3.508 \\
$\begin{array}{l}\text { surgical admission) } \\
\text { Mechanical ventilation }\end{array}$ & 0.000 & 2.081 & 1.547 & 2.800 \\
Vasopressors or & 0.000 & 1.707 & 1.441 & 2.022 \\
inotropes & & & 1.317 & 1.913 \\
Any cancer & 0.000 & 1.567 & 1.236 & 1.986 \\
Infection on the study & 0.031 & 1.404 & 1.032 & 1.910 \\
day & & & & \\
Closed ICU (vs open ICU) & 0.002 & 1.398 & 1.131 & 1.727 \\
Hospital size ( $\geq 500$ beds & 0.000 & 1.355 & 1.143 & 1.607 \\
vs 1-499 beds) & & & & \\
SOFA score & 0.000 & 1.077 & 1.039 & 1.117 \\
APACHE II score & 0.000 & 1.044 & 1.029 & 1.058 \\
\hline . Varibb not signicant: & & & & \\
\hline
\end{tabular}

a. Variable not significant: age, immunosuppressive therapy, presence of heart failure, dialysis-dependent, sepsis, need for RRT, adequately equipped, respiratory system dysfunction or failure, ICU teaching, number of ICU beds

$\mathrm{Cl}$, confidence interval; ICU, intensive care unit; SOFA, sequential organ failure assessment; APACHE, acute physiology and chronic health evaluation process of care. The role of open and hybrid ICUs requires further study, and legal and procedural issues related to end-of-life care need to be resolved.

\section{Author Contributions}

Conception or design of the work: Jigeeshu V Divatia, Yatin Mehta, Deepak Govil, Kapil Zirpe, Pravin R Amin, Nagarajan Ramakrishnan, Farhad N Kapadia, Subhash K Todi.

Acquisition, analysis, or interpretation of data for the work; Jigeeshu V Divatia, Yatin Mehta, Deepak Govil, Kapil Zirpe, Pravin R Amin, Nagarajan Ramakrishnan, Farhad N Kapadia, Mrinal Sircar, Samir Sahu, Pradip K Bhattacharya, Sheila N Myatra, Srinivas Samavedam, Subhal Dixit, Rajesh K Pande, Sujata N Mehta, Ramesh Venkatraman, Khusrav Bajan, Vivek Kumar, Rahul Harne, Leelavati Thakur, Darshana Rathod, Prachee Sathe, Sushma Gurav, Carol D'Silva, Shaik A Pasha, Subhash K Todi.

Drafting the work or revising it critically for important intellectual content: All authors.

Final approval of the version to be published: All authors.

Agreement to be accountable for all aspects of the work in ensuring that questions related to the accuracy or integrity of any part of the work are appropriately investigated and resolved: All authors.

Table 8: ICU and patient characteristics and outcomes in INDICAPS ${ }^{1}$ and INDICAPS-II

\begin{tabular}{|c|c|c|c|}
\hline Characteristic & INDICAPS & INDICAPS-II & Remarks \\
\hline Number of ICUs & 120 & 132 & \\
\hline Number of patients & 4,038 & 4,669 & \\
\hline Age (years) (mean $\pm S D)$ & $54.1 \pm 17.1$ & $56.9 \pm 17.4$ & \\
\hline Male patients (\%) & 66.1 & 63.7 & \\
\hline APACHE II score & $17.4 \pm 9.2$ & $16.7 \pm 9.8$ & \\
\hline SOFA score (mean \pm SD) & $3.8 \pm 3.6$ & $4.4 \pm 3.6$ & \\
\hline ICU stay, days [median, (IQR)] & $6[3-13]$ & $6[3-13]$ & \\
\hline Patients dying in ICU (\%) & 13.5 & 15.8 & \\
\hline Terminal discharges (\%) & 4.5 & 7.6 & \\
\hline Total ICU mortality (\%) & 18.1 & 23.4 & \\
\hline Open ICUs (\%)/patients in open ICUs (\%) & $74.2 / 78.0$ & $84.8 / 84.4$ & \\
\hline $\begin{array}{l}\text { Mixed medical-surgical ICUs (\%)/patients in mixed } \\
\text { medical-surgical ICUs (\%) }\end{array}$ & $80.8 / 83.1$ & $81.8 / 87.4$ & \\
\hline ICUs with >20 beds (\%)/patients in ICUs with > 20 beds (\%) & $25.0 / 37.0$ & $49.2 / 68.1$ & \\
\hline $\begin{array}{l}\text { Hospitals with } \geq 500 \text { beds (\%)/patients in hospitals with } \geq 500 \text { beds } \\
\text { (\%) }\end{array}$ & $35 / 46.6$ & $36.4 / 47.5$ & \\
\hline $\begin{array}{l}\text { ICUs with nurse:patient ratio }<1: 2(\%) / \text { patients in ICUs with } \\
\text { nurse:patient ratio }<1: 2(\%)\end{array}$ & $30.8 / 45.6$ & $34.1 / 25.8$ & \\
\hline Public hospital ICUs (\%)/patients in public hospital ICUs (\%) & $10.8 / 9.7$ & $4.5 / 2.4$ & \\
\hline $\begin{array}{l}\text { ICUs with a postgraduate teaching program in intensive care (\%)/ } \\
\text { patients in ICUs with a postgraduate teaching program in intensive } \\
\text { care (\%) }\end{array}$ & $39.2 / 64.9$ & $72.0 / 82.6$ & \\
\hline $\begin{array}{l}\text { Adequately equipped ICUs (\%)/patients in adequately equipped } \\
\text { ICUs (\%) }\end{array}$ & $67.5 / 87.4$ & $47.0 / 61.1$ & $\begin{array}{l}\text { Criteria for adequately equipped ICUs } \\
\text { were different between the two studies }\end{array}$ \\
\hline Self-paying patients, (\%) & 80.5 & 64.5 & \\
\hline Medical or nonoperative patients & 77.1 & 85.5 & \\
\hline Patients with suspected or confirmed infection on the study day (\%) & 36.0 & 25.6 & \\
\hline Sepsis and/or septic shock during ICU stay (\%) & 28.3 & 29.3 & $\begin{array}{l}\text { Criteria for diagnosis of sepsis were } \\
\text { different between the two studies }\end{array}$ \\
\hline
\end{tabular}


Table 8: (Contd...)

\begin{tabular}{|c|c|c|c|}
\hline Characteristic & INDICAPS & INDICAPS-II & Remarks \\
\hline Poisoning or overdose & 3.1 & 1.5 & \\
\hline Invasive mechanical ventilation (\%) & 31.1 & 24.1 & \\
\hline ICU mortality in patients receiving invasive mechanical ventilation (\%) & 35.6 & 44.4 & \\
\hline Patients receiving renal replacement therapy (\%) & 12.0 & 9.3 & \\
\hline ICU mortality in patients receiving renal replacement therapy (\%) & 31.5 & 41.7 & \\
\hline Patients receiving vasopressors/inotropes (\%) & 22.2 & 22.2 & \\
\hline ICU mortality in patients receiving vasopressors/inotropes (\%) & 36.1 & 44.0 & \\
\hline Invasive blood pressure monitoring (\%) & 19.5 & 25.4 & \\
\hline Central venous catheter inserted (\%) & 34.6 & 34.3 & \\
\hline Blood lactate measured (\%) & 11.3 & 31.6 & \\
\hline
\end{tabular}

INDICAPS, Indian intensive care unit case-mix and practice patterns study; ICU, intensive care unit; APACHE, acute physiology and chronic health evaluation; SOFA, sequential organ failure assessment

\section{ORCID}

Jigeeshu V Divatia @ https://orcid.org/0000-0001-7384-4886

Yatin Mehta $\odot$ https://orcid.org/0000 000208884774

Deepak Govil @ https://orcid.org/0000-0002-4624-1614

Kapil Zirpe 이 https://orcid.org/0000-0002-8140-727X

Pravin R Amin (1) https://orcid.org/0000-0002-9865-2829

Nagarajan Ramakrishnan (1) https://orcid.org/0000-0001-5208-4013

Farhad N Kapadia (1) https://orcid.org/0000-0003-1837-1144

Mrinal Sircar $\odot$ https://orcid.org/0000-0002-2199-3318

Samir Sahu 구 https://orcid.org/0000-0003-1246-3187

Pradip Kumar Bhattacharya $\odot$ https://orcid.org/0000-0002-0219-385X

Sheila Nainan Myatra @ https://orcid.org/0000-0001-6761-163X

Srinivas Samavedam @ https://orcid.org/0000-0001-6737-8663

Subhal Dixit @ ittps://orcid.org/0000-0002-1441-0807

Rajesh Kumar Pande ㄷ https://orcid.org/0000-0002-0149-727X

Sujata N Mehta $\odot$ https://orcid.org/0000-0003-0306-538X

Ramesh Venkataraman (1) https://orcid.org/0000-0003-1949-3979

Khusrav Bajan (1) https://orcid.org/0000-0002-7339-4288

Vivek Kumar (1) https://orcid.org/0000-0002-6914-5422

Rahul Harne 우 https://orcid.org/0000-0002-0178-2628

Leelavati Thakur @ https://orcid.org/0000-0002-1592-7592

Darshana Rathod (1) https://orcid.org/0000-0002-5446-6768

Prachee Sathe ㄴ https://orcid.org/0000-0002-1236-1669

Sushma Gurav @ https://orcid.org/0000-0001-6875-2071

Carol D'Silva 이 https://orcid.org/0000-0002-3920-1366

Shaik Arif Pasha @ https://orcid.org/0000-0001-6314-8473

Subhash Kumar Todi 으 https://orcid.org/0000-0003-2306-6080

\section{Supplementary Material}

All the supplementary material from Supplementary tables 1-5 are available online on the website of www.IJCCM.org

\section{References}

1. Divatia JV, Amin PR, Ramakrishnan N, Kapadia FN, Todi S, Sahu S, et al. Intensive care in India: The Indian intensive care case mix and practice patterns study. Indian J Crit Care Med 2016;20(4):216-225. DOI: 10.4103/0972-5229.180042.

2. Knaus WA, Wagner DP, Draper EA, Zimmerman JE, Bergner M, Bastos PG, et al. The APACHE III prognostic system. Risk prediction of hospital mortality for critically ill hospitalized adults. Chest 1991;100:1619-1636. DOI: 10.1378/chest.100.6.1619.
3. Knaus WA, Draper EA, Wagner DP, Zimmerman JE. APACHE II: a severity of disease classification system. Crit Care Med 1985;13(10):818-829.

4. Ferreira FL, Bota DP, Bross A, Mélot C, Vincent JL. Serial evaluation of the SOFA score to predict outcome in critically ill patients. JAMA 2001;286(14):1754-1758. DOI: 10.1001/jama.286.14.1754.

5. Singer M, Deutschman CS, Seymour CW, Shankar-Hari M, Annane D, Bauer $M$, et al. The third international consensus definitions for sepsis and septic shock (sepsis-3). JAMA 2016;315(8):801-810. DOI: 10.1001/ jama.2016.0287.

6. Mani RK. End-of-life care in India. Intensive Care Med 2006;32: 1066-1068. DOI: 10.1007/s00134-006-0185-7.

7. Devlin JW, Skrobik Y, Gélinas C, Needham DM, Slooter AJC, Pandharipande PP, et al. Clinical practice guidelines for the prevention and management of pain, agitation/sedation, delirium, immobility, and sleep disruption in adult patients in the ICU. Crit Care Med 2018;46(9):e825-e873. DOI: 10.1097/CCM.0000000000003299.

8. Aruna Ramachandra Shanbaug vs the Union of India \& Ors. WRIT Petition (CRIMINAL) No. 115 of 2009 (Supreme Court of India Proceedings); 2009.

9. Ramakrishnan N, Ranganathan L, Abraham BK, Rajagopalan S, Venkataraman R. What happens to patients discharged against medical advice? Indian J Crit Care Med 2018;22(8):580-584. DOI: 10.4103/ijccm.IJCCM_101_18.

10. Brilli RJ, Spevetz A, Branson RD, Campbell GM, Cohen H, Dasta JF, et al. Critical care delivery in the intensive care unit: Defining clinical roles and the best practice model. Crit Care Med 2001;29(10):2007-2019. DOI: 10.1097/00003246-200110000-00026.

11. Critical care delivery in intensive care units in India: defining the functions, roles and responsibilities of a consultant intensivist: recommendations of the Indian Society of Critical Care Medicine Committee on defining the functions, roles and responsibilities of a consultant intensivist. Available from: https://isccm.org/pdf/ ISCCM\%20Intensivist\%20guidelines.pdf [Last cited on June 07, 2021].

12. Rungta N, Zirpe KG, Dixit SB, Mehta Y, Chaudhry D, Govil D, et al. Indian Society of Critical Care Medicine experts committee consensus statement on ICU planning and designing, 2020. Indian J Crit Care Med 2020;24(Suppl. 1):S43-S60. DOI: 10.5005/jp-journals-10071-G23185.

13. Checkley W, Martin GS, Brown SM, Chang SY, Dabbagh O, Fremont RD, et al. Structure, process, and annual ICU mortality across 69 centers: United States critical illness and injury trials group critical illness outcomes study. Crit Care Med 2014;42(2):344-356. DOI: 10.1097/ CCM.0b013e3182a275d7.

14. Kashyap R, Vashistha K, Saini C, Dutt T, Raman D, Bansal V, et al. Critical care practice in India: results of the intensive care unit need assessment survey (ININ2018). World J Crit Care Med 2020;9(2):31-42. DOI: 10.5492/wjccm.v9.i2.31.

15. Kartik M, Gopal PBN, Amte R. Quality indicators compliance survey in Indian intensive care units. Indian J Crit Care Med 2017;21(4):187-191. DOI: 10.4103/ijccm.IJCCM_164_15. 
16. Levy MM, Rapoport J, Lemeshow S, Chalfin DB, Phillips G, Danis M. Association between critical care physician management and patient mortality in the intensive care unit. Ann Intern Med 2008;148(11): 801-809. DOI: 10.7326/0003-4819-148-11-200806030-00002.

17. Sakr Y, Moreira CL, Rhodes A, Ferguson ND, Kleinpell R, Pickkers $P$, et al. The impact of hospital and ICU organizational factors on outcome in critically ill patients: results from the extended prevalence of infection in intensive care study. Crit Care Med 2015;43(3):519-526. DOI: 10.1097/CCM.0000000000000754. PMID: 25479111.
18. Vincent JL, Sakr Y, Singer M, Martin-Loeches I, Machado FR, Marshall JC, et al. Prevalence and Outcomes of infection among patients in intensive care units in 2017. JAMA 2020;323(15):1478-1487. DOI: 10.1001/jama.2020.2717. PMID: 32207816; PMCID: PMC7093816.

19. CookTM, Woodall N, Harper J, Benger J; Fourth National Audit Project. Major complications of airway management in the UK: results of the Fourth National Audit Project of the Royal College of Anaesthetists and the Difficult Airway Society. Part 2: intensive care and emergency departments. Br J Anaesth 2011;106(5):632-642. DOI: 10.1093/bja/ aer059. 


\section{Appendix}

\section{INDICAPS-II Investigators}

Neeraj Kumar, Amarjeet Kumar, All India Institute of Medical Sciences, Patna

Dipak Kumar Agarwal, Sarat Kumar Behera, AMRI Hospital, Bhubaneswar

Susruta Bandyopadhyay, Rajarshi Roy; AMRI Hospital, Salt Lake, Kolkata

Samir Sahu, Rajeshree Nandy; AMRI Hospitals, Bhubaneswar

Sushmita Basu; AMRI Hospitals, Mukundapur, Kolkata

Subhash Kumar Todi, Saswati Sinha; AMRI, Dhakuria, Kolkata

Lawni Goswami; Apollo Gleneagles Hospital, Kolkata

Manoj Kumar Singh, Jay Kothari; Apollo Hospital International Ltd,

Ahmedabad

Vilas Kushare, Pravin Tajane, Apollo Hospitals, Nashik

Banambar Ray, Sharmili Sinha, Saroj Pattnaik; Apollo Hospitals, Bhubaneswar

Nagarajan Ramakrishnan, Ramesh Venkataraman; Apollo Hospitals, Chennai

Reshma Tewari, Sujan Dey; Artemis Health Institute, Gurugram

Ruchira Khasne, Ashoka Medicover Hospital, Nashik

Prasanna Kumar Mishra, Sampat Dash; Ashwini Hospital, Cuttack

Sandip Bhattacharyya; Asian Institute of Medical Sciences, Faridabad

Vandana Sinha, Anup Jyoti Dutta; Ayursundra Superspecialty Hospital, Guwahati

Praveen Kumar Koppula, Krishna Prabhakar Kasam, Basanth Kumar Rayani, Abhijit Sukumaran Nair; Basavatarakam Indo American Cancer Hospital and Research Institute, Hyderabad

Jignesh Navinchandra Shah, Prashant Jedge; Bharati Vidyapeeth (Deemed to be University) Medical College, Pune

A Chakravarthi; Billroth Hospital, Chennai

Amol Hartalkar; BKL Walawalkar Rural Medical College and Hospital, Chiplun

Rajesh Kumar Pande, Abhishek Vishnu; BLK Superspeciality Hospital, Delhi

Pravin R Amin, Sujata N Mehta; Bombay Hospital and Medical Research Center, Mumbai

Kalpesh Bhoyar, Joanne Mascarenhas; Breach Candy Hospital, Mumbai

Madhusudan R Jaju; CARE Hospital, Nampally, Hyderabad

Venkat Raman Kola, Hariprasad; Care Hospital Banjara Hills, Hyderabad

T Mohan S Maharaj, Lakshmi Rani Takkellapati; Care Hospitals, Visakhapatnam

Sunil T Pandya, Kiran M; Century Super Specialty Hospital, Hyderabad

Akshay Shrivastava, Pallavi Shrivastava; Chirayu Hospital, Rewa

Pradip K Bhattacharya, Nimita Deora; Chirayu Medical College and Hospital, Bhopal

Anand Sanghi; Choithram Hospital and Research Centre, Indore

Abhishek Samprathi, Kishore Pichamuthu; Christian Medical College, Vellore

Bhagyesh Shah, Shuchi Kaushik; CIMS Hospital, Ahmedabad

Palepu B Gopal, Ch. Balasubrahmanyam; Continental Hospitals, Hyderabad

Deepak Jeswani, Deepti Jeswani; Criticare Hospital and Research Institute, Nagpur
Shruti Sharma, Gunchan Paul; Dayanand Medical College and Hospital, Ludhiana

Prasad Rajhans, Safal Sable; Deenanath Mangeshkar Hospital, Pune Chaitri Shah, JD Lakhani; Dhiraj Hospital SBKSMIRC, Vadodara

Arpita Dwivedy, Priteema Chanana; Dr LH Hiranandani Hospital, Mumbai

Vaibhav Bhargava, Pramod Sarwa, Kishore Mangal, Yatendra Kumar Gupta; Eternal Hospital, Jaipur

Vivek Nangia, Amina Mobashir; Fortis Hospital, Vasant Kunj, New Delhi

Mrinal Sircar, Saurabh Mehra; Fortis Hospital, Noida

Arun Kumar, Amit Kumar Mandal; Fortis Hospital, Mohali

VK Thakur; Paras HMRI Hospital, Patna

Sandeep Patil; Fortis Hospitals, Kalyan

Bhushan Kinholkar; Galaxy Care Hospital, Pune

Neeta Bose, Dhara Tanna; GMERS Gotri Medical College, Vadodara Bhavik V Shah, Priyanka Khatri; HCG Hospitals, Ahmedabad

Nishchil H Patel, Sanjoy Joseph George; Holy Family Hospital, Thodupuzha, Kerala

Sanghamitra Mishra, Basanta Kumar Pati; IMS and SUM Hospital, Bhubaneshwar

Rajesh Chawla, Sudha Kansal; Indraprastha Apollo Hospitals, New Delhi

Atul Kumar Singh, Sulakshana; Institute of Medical Sciences, BHU, Varanasi

Leelavati Thakur; IQ City Medical College and Narayana MultiSpecialty Hospital, Durgapur

Shruti Tandan, Varun Deshmukh; Jaslok Hospital, Mumbai

Gyanendra Agrawal, Deepak Singhal; Jaypee Hospital, Noida

Narendra Rungta, Neena Rungta; JNU Institute of Medical Sciences and Research Center, Jaipur

Om Prakash Shrivastava, Satnam Singh; Kothari Medical and Research Institute, Bikaner

Vivek Kumar, Srinivasan Ramananthan; Lilavati Hospital and Research Centre, Mumbai

Dipak Aghara, Jayendra Aghara; Mangalam Hospital, Morbi

Rajesh Mohan Shetty, Manjunath Thimmappa; Manipal Hospital Whitefield, Bengaluru

Shantanu Belwal, Bhupesh Uniyal, Rekha Gupta, Mudit Garg; Max Superspeciality Hospital, Dehradun

Yatin Mehta, Deepak Govil, Shaleen Bhatnagar, Chitra Mehta, Prashant Kumar, Tariq Ali, Rahul Harne; Medanta-The Medicity, Gurgaon

Payel Bose, Saurabh Debnath; Medica Superspecialty Hospital, Kolkata

Lalit Singh, Nipun Agrawal; Shri Ram Murti Smarak Institute of Medical Sciences, Bareilly

Ajay A Bulle; Meditrina Institute of Medical Sciences, Nagpur Ajita Annachhatre, Yogesh Belapurkar; Mahatma Gandhi Mission's Medical College and MCRI Superspeciality Hospital, Aurangabad Kanwalpreet Sodhi, Harmanpreet Kaur; Deep Hospital, Ludhiana AS Ansari, Sourabh Phadtare, Ranjit Sousa, Minal Jariwala, Yuti Sheth, Gunjan Chanchalani; Nanavati Superspecialty Hospital, Mumbai Harish Mallapura Maheshwarappa, Ramya BM; Narayana Hrudayalaya, Bengaluru

Sachin Gupta, Deeksha Singh Tomar; Narayana Super Speciality Hospital, Gurugram 


\section{Appendix}

Utpal Sarma, Vipul Mishra; Nayati Medicity, Mathura Sultana Teslima Begum, Ajit Deka; Nemcare Hospital, Guwahati Sunitha Binu Varghese, Ajit Yadav; Niramaya Hospital, Pune Shaik Arif Pasha, V Chittaranjan Naidu, Lakshmi Prasannam; NRI Medical College and General Hospital, Guntur Pankaj Patil; Ozone Multispeciality Hospital, Akola

Farhad N Kapadia, Khusrav Bajan; PD Hinduja National Hospital and MRC, Mumbai

Ajoy Krishna Sarkar; Peerless Hospital, Kolkata Diptimala Agarwal; Pushpanjali Hospital, Agra

Simant Kumar Jha, Shiv Kumar; Pushpawati Singhania Research Institute, New Delhi

Kapil Zirpe, Sushma Gurav, Prajakta Wankhede, Prachee Sathe, Prashant Sakhavalkar, TR Jadhav; Ruby Hall Clinic, Pune

Shilpa Kulkarni, Saurabh Shaha; Ruby Hall Clinic, Pune

Sanjith Saseedharan, Roopa Karanam; S L Raheja Hospital, Mumbai; Promise Jain; Sagar Shree Hospital, Sagar

Subhal Dixit, Priyanka Khalate; Sanjeevan Hospital, Pune

Nikhil Ajmera, Geetesh Mangal; Santokba Durlabhji Memorial Hospital, Jaipur

AS Arunkumar, Kalaiselvan MS; Saveetha Medical College and Hospital, Chennai

A Mohana Rao, V Kuchela Babu; Sevenhills Hospital, Visakhapatnam Vishal Sadatia, Tushar Patel; Shree Giriraj Multi-Specialty Hospital, Rajkot

Abhishek Prajapati, Deepak S Sharma; Shree Krishna Hospital, Anand
Krutika Tandon; Shree Krishna Hospital, Karamsad Nitinkumar B Agarwal, Basavraj Pujari; Shri Ganpatlal Agarwal Memorial Ayush Multi-Specialty Hospital and Research Center, Bijapur

Sudhir Khunteta; Shubh Hospital, Jaipur

Darshana Rathod; Sir H N Reliance Foundation Hospital, Mumbai

Ankur Bhavsar; Spandan Multispeciality Hospital, Vadodara

NK Vinod, Bharath KV; Sri Shankara Cancer Hospital and Research Center, Bengaluru

Carol Dsilva, Bhuvana Krishna; St John's Medical College Hospital, Bengaluru

Harjit Dumra, Mansi Dandnaik; Sterling Hospital, Ahmedabad

Anand V Joshi; Sunshine Hospitals, Gachibowli, Hyderabad

Nirmal Jaiswal, Shivam Chopra; Suretech Hospital, Nagpur

Ranvir Singh Tyagi, Rakesh Kumar Tyagi; Synergy Plush Hospital, Agra

Milap Mashru, Jayeshkumar Dobariya; Synergy Multi Superspeciality Hospital, Rajkot

Jigeeshu V Divatia, Sheila Nainan Myatra, Atul P Kulkarni, Anjana Shrivastava, Amit Narkhede; Tata Memorial Hospital, Mumbai

Bharat Jagiasi, Pallavi Patekar; Terna Speciality Hospital and Research Centre, Navi Mumbai

Shyam Sunder Tipparaju, Yalavarthy Swathi; Thumbay Hospital, Hyderabad

Himansu Sekhar Mishra, N Srinivas; Vikash Multispecialty Hospital, Bargarh

Srinivas Samavedam, Narmada Aluru; Virinchi Hospital, Hyderabad 